\title{
EDUCATING FOR SUCCESS \\ A Program to Enhance the Self Concept of Freshmen on a Large College Campus: An Evaluation
}

\section{LILA SWELL $\dagger$}

\begin{abstract}
A pre/post analysis of 6 instruments administered over 2 semesters for EFS* vs control group Freshmen students revealed that the EFS program was effective in increasing positive self attitudes.
\end{abstract}

\section{Résumé}

Une étude prélposte analyse de six instruments administrés au cours de deux semestres à deux groupes d'étudiants de première année, dont l'un participait au programme "Educating for Success", montre que le programme a réussi à développer chez les étudiants participants des attitudes plus positives envers eux-mémes.

Liberal admissions policies, including complete open enrollment; have flooded colleges and universities with students who are unprepared for college work. The number of these students has risen to such proportions that the colleges have been faced with high rates of withdrawal after the freshman year.

Freshmen entering a large university environment are faced with the awesome necessity of choosing from a bewildering number of paths- personal as well as academic. The anxieties of coping with these choices, coupled with the impersonality of computerized student accounting, could not be felt more keenly by any other group than by entering college freshmen. For no other group of students is making a correct choice more critical than for young people about to commit themselves to four years of college. For a majority, the choices made during this time will certainly influence and perhaps determine, the direction of their lives.

For one to make decisions with such far-reaching consequences, one needs to know oneself. The relationship between an individual's self concept and the

$\dagger$ Associate Professor of Educational Psychology, Department of Elementary and Early Childhood, Queens College, Flushing, N.Y.

* Educating For Success 
eventual choices made concerning his or her life roles is of key importance. Students' personal evaluations of themselves are a dominant influence on their academic achievement. Numerous research studies (e.g., Burke, 1985; Pottebaum, 1986; Tunney, 1984) have substantiated this theory.

Educating For Success is an experiential program (Swell, 1990) designed to enable the students to find out who they think they are, what their strengths and values are, and what strategies they use to manage conflict. Armed with this vital information about who they are and how they operate, the students can make more informed vocational choices, optimize their performance and thereby increase their probability of success.

Specifically, the goals of EFS are:

- To develop the skills to identify and analyze patterns of success in self and others

- To develop awareness of ego strengths in self and others

- To foster recognition and acceptance of a stable personal value system

- To identify one's conflict management styles and to learn alternative problem-solving techniques

- To define, set, and act on realistic goals for self

In order to achieve these goals, students go through five phases of the EFS Program. A description of each phase follows.

\section{Phase I - Success Analysis}

Participants are asked to list three successes from each of the age ranges $0-7$, $8-12,20$-present. They also are asked to give the reasons why they consider these events successes. The group analyzes each chart and derives the individual's "success patterns." Each participant then formulates a personal definition of success.

For example, suppose a participant (call him John Smith) had a success chart on which some of the successes were:

When I was seven years old, I had a shoeshine stand and made enough money to buy a bicycle.

During the summer when I was fifteen, I bought an old car from the junk yard for $\$ 50$. After working all summer and investing $\$ 200$ fixing it up, I sold it for $\$ 600$.

At age eighteen, I had a handicraft booth at the school bazaar and made enough money to go to Hawaii over the Christmas vacation. 
In analyzing the pattern of these successes several themes are apparent:

He starts from "scratch" and builds things up - by himself.

He has goals that usually cost money.

He is very resourceful in the way he approaches a problem.

He seems very optimistic that, if he starts a project, he will complete it successfully.

These are just some of the statements that can be made about his personal idea of what success means to him. In light of these patterns, it probably would be foolish for John to decide to become a librarian, a career naval officer, a civil servant, or, in short, to become involved in any job in which he would not perform independently and realize a concrete reward. Without understanding his own personal definition of success, he could well embark on a career course that could be frustrating, unsatisfying, and burn up inordinate amounts of time. With the insight gained from participating in the EFS program, he would be less likely to make such a choice.

\section{Phase II - Strength Bombardment}

In the Strength phase, each participant is assisted by the group in abstracting from his or her list of successes those strengths which were used in personal achievements. Continuing to use John Smith as an example, a list of the strengths he used to create his successes would include independence, resourcefulness, creativity, determination, etc. Each member of the group makes up a list of John's strengths and bombards him with it. Along with telling him a strength, each must tell him the evidence used for inferring the strength. The specificity and evidence heighten the credibility of the bombarder in the eyes of the bombarded. An underlying assumption of EFS is that all individuals have solid strengths which are presently unidentified and, thus, unused. The word "strength" refers to any skill, talent, ability, or personal trait.

\section{Phase III - Value Identification}

Consideration of values is crucial to the understanding of the individual's functioning, especially in decision-making and goal-setting. Since values have a definite influence on an individual's choices, it is important not only to understand what values are, but also to understand how they developed. How are values acquired? How are they presently operative in the individual's behaviour patterns, which include his choices, decision-making, and goals? 
What are values? There is no one standard definition dominating the literature; almost every writer has constructed his own definition. For the purpose of this program, values may be defined as the standards of desirability by which the individual chooses between alternate behaviours. They are the guides by which choices or decisions are made. Values are motivating factors in determining goals; they also help us in defining success and in achieving success through accomplishing our goals.

EFS helps the individual to move through three levels of value development. The first level, acceptance of the value, is achieved as individuals discuss their own values and those of others. The second level, preference for the value, is achieved as the individual investigates his or her own value structure, which is the ranked order of personal values according to their importance to the individual. The third level, commitment to the value, is achieved as the individual is encouraged to set goals reflecting personal values. Values and action thus are linked in the group experience and, we hope, in the individual's total life process.

\section{Phase IV - Conflict Management}

Conflict can either prevent an individual from achieving goals or help the individual to achieve the goals. Whether it will help or hinder is determined by the way in which the individual manages this conflict. EFS seeks to help in the movement from the negative methods of conflict management which prevent achievement of goals, to the positive methods which help in their achievement. This is done by helping individuals to learn new, constructive, positive methods of conflict management, and to unlearn any destructive, negative methods they may have employed in the past. The focus is on learning new patterns and unlearning old patterns. The students first identify their own techniques for dealing with conflict. They are then exposed to a variety of Conflict Management styles. Problem situations are presented via several media: role playing, video tape, story vignettes.

\section{Phase V - Reinforcement}

The foregoing phases are a tightly interrelated system of reinforcement - each phase building on the one before, each phase doing the same thing on a new. level. Perhaps the best visual image of how these phases work together would be a spiral, each new turn covering the same ground, but always moving to a higher plane. Another way of expressing the interrelationship would be to say 
that each phase somehow presupposes all the previous phases. In order to determine what your prioritized value system is and what your predominant strengths are, you must identify which values have directed and which strengths have effected the successful management of conflicts in the past. In other words, how do your values and strengths cooperate to produce constructive behaviour patterns? A similar statement could be made about each phase to express its relation to the others and to show that in each phase there is a dynamic of reinforcement at work separate from preceding ones. This interrelationship among the phases is in itself reinforcing in that all principles are repeated and built upon in all phases. There is thus a natural progression in the learning process.

Goal-setting is perhaps the single most important aspect of reinforcement because the setting and completion of realistic goals may lead to more successful functioning. There are very specific prior constraints against which a potential goal must be measured before it is selected. What these constraints do is maximize the probability that the goal will be achieved. The constraints are as follows:

1. Believable (can be accomplished using your innate strengths and abilities)

2. Controllable (subject to personal control)

3. Measurable (can be expressed quantitatively)

4. Desirable (something a person really wants to do)

5. Growth facilitating (non-injurious to self, others, and society)

An example of a goal that meets these constraints is the following: I am going to write five pages for my homework assignment this week.

Once the students have reached this phase of the program, completion of old goals is reported and new goals are set at each session. By repeating this behaviour, goal-setting becomes an integral part of the individual's behavioral repertoire. The repetition facilitates the internalization of the goal-setting process. The students are taught to partialize, and to process by focusing on the achievement of a series of small short range goals in order to achieve larger, more significant, long-range goals.

After completing the strength phase, the students are first asked to set goals related to their strengths. Later in the program, these goals are related to other strengths and values. Finally, the individuals are encouraged to set goals related to the positive management of future conflicts. It is then explained that, in order to manage conflict positively, it is necessary to understand conflict (What 
values are involved?) and to utilize strengths creatively (What strengths can I use? How can I use them?). Through this progressive integration of EFS principles in action, each individual principle is reinforced and all principles are bonded together in a unified whole.

\section{Method}

In order to determine the effectiveness of the "Educating for Success" program for college freshmen, a battery of tests was administered over a two semester period to two samples of students. Each sample consisted of two groups - an experimental and a control group.

The two groups in each sample were drawn from participants in eight sections of the EFS program (Experimental) and eight sections of English 1 (Control). The Sample 1 groups were selected in the Fall semester; Sample 2 groups in the Spring. Data for both Sample 1 and 2 were collected by means of the following test instruments: EFS Expectation Scales 1 \& 2 (administered to EFS students only), EFS Personal Inventory (3 parts) and College Life Inventory. Both between-group and within-group pre/post-test designs were employed. Testing was administered on the very first and last day of classes during the Fall and Spring semesters.

\section{Instruments: A Description}

The EFS Expectation Scale consists of a two part Pyramid Expectancy Scale and measures the students' attitudes to the course itself. The first part, Scale 1, contains 20 Likert-type items constructed by students in a Psychology Test and Measurement class and standardized on 40 EFS students, 20 males and 20 females. No significant sex differences were found in this study. The second part of the expectation scale, Scale 2, contains 20 bipolar items constructed by the same students and standardized on the same sample. For both scales, the range of possible scores is $20-100$. A score of 60 indicates the neutral position, scores above 60 are favourable or indicate generally positive expectations.

A sample item from Scale 1 is "Special talents and strengths will be developed in this course." The student's response is one of 5 choices ranging from 'strongly agree' through 'undecided' to 'strongly disagree'. A sample item of Scale 2 is "EFS will help toward - will not help toward success in career." The student's response is one of 5 choices indicating the degree of enthusiasm for the proposition ranging from 'very positive' through 'neutral' to 'very negative'.

The second instrument, Personal Inventory, consists of three parts: A. In the 
pre-test the student is asked to select three adjectives or phrases which the stu$\operatorname{dent}(\mathrm{s})$ feels best describes him or her; in the post-test the student is asked to select from a cluster of synonym/antonym pairings formed from the pre-test results. Seventeen clusters were formed from the pre-test results; ten of these were opposite pairs so the total number of categories was 27. (Joseph Devlin's Dictionary of Synonyms and Antonyms was used to form the pairings.) An example of the paired cluster formed from the pre-test responses is: $(+)$ cheerful, enthusiastic, filled with dreams and hopes, fun, funny, happy, optimistic, positive view, sense of humour; (-) discontented, pessimistic. "Musical" is an example of the unpaired cluster, since no one on the pretest selected "non-musical" as a self descriptor. B. The student is asked to complete ten sentences designed to provide self-report criteria, e.g., I am a person who ; and, C. the student is asked to rate his or her attitude toward life in general on a 0-10 scale of Optimism-Pessimism (O-P).

The last instrument, College Life Inventory, consists of 15 scenes typical of College Life for Sample 1, and 10 of the original 15 for Sample 2. These were taken from the annual report of the Educational Testing Services, Princeton, N.J., and from two reports of critical incidents. The student is required to entitle the picture, and then to rate it with a positive, negative, or neutral response.

\section{Instruments: Scoring}

In scoring Part A of the Personal Inventory, Three Adjectives, the responses for each cluster were stratified by the EFS/Control and Pre/Post. The percentage of responses for each group was calculated and the difference between thepre and post percentages was used to establish significance levels between pre- and post- responses for EFS and Control groups separately, by category.

For part B, Sentence Completion scoring was determined on the basis of the responses in the original sample. There were three categories of responses positive, negative, or neutral. The final score consists of the total number of positive responses made by each student for the ten sentences completed. In order to identify the sentences where change occurred, a breakdown was compiled of positive, negative, and neutral responses for Sample 2, separated by EFS/Control and Pre/Post. It was hypothesized that responses would increase in a positive direction.

Scoring of Part C, the O-P scale, was calculated by taking the number indicated by the student on a self-rating scale of $0-10$. This was hypothesized to increase on the post-test.

Scoring of the College Life Inventory instrument consists of the total number 
of positive responses for each student. This was expected to increase for EFS students on the post-test.

\section{Discussion of Results}

Responses to Part A of the Personal Inventory ( 3 adjectives) showed significant changes in several categories for the experimental groups.

The hypothesis was that more positive, and thus fewer negative, adjectives will be selected by the EFS students after they complete the course, and that the selections of the Control group will not change. A change of $2 \%$ in any category was established as a significant movement. Because the Control groups were roughly one-third the size of the EFS groups, a change of $6 \%$ was set as the standard.

Table 1 shows the categories in which significant movement occurred. For the EFS groups, six categories representing positive attitudes toward self,

Table 1

Categories Showing Significant Changes Between Pre-and Post-tests For. The EFS Personal Inventory Instrument - Part A. (Three Adjectives)

Percentage Difference

EFS Control
Category

(Positive)

1. caring, compassionate

2. enthusiastic, cheerful

3. fair, honest, open-minded

4. analytical, intelligent

5. easygoing, generous

7. independent, self-reliant

8. energetic

(Negative)

-5 moody, insecure

-6 introverted, shy

$\begin{array}{cccc}\begin{array}{c}\text { Spring } \\ (\mathrm{n}=167)\end{array} & \begin{array}{c}\text { Fall } \\ (\mathrm{n}=147)\end{array} & \begin{array}{c}\text { Spring } \\ (\mathrm{n}=34)\end{array} & \begin{array}{c}\text { Fall } \\ (\mathrm{n}=46)\end{array}\end{array}$

$\begin{array}{cccc}- & 7.4 \% & - & 8.4 \% \\ - & - & 6.1 \% & -\end{array}$

$3.1 \%$

$2.9 \%$

$2.1 \%$

-

$2.2 \%$

$-3.7 \%$

$-5.3 \%$ 
showed increases of at least $2 \%$; two categories, representing negative self opinion, were reduced by more than $2 \%$; changes in the remaining categories were not large enough to be meaningful. The Control group showed meaningful changes in two categories; the changes represented increased positive attitudes toward themselves. No other significant movements were made by the Control groups.

After completing the program, EFS students felt that they were more caring, cheerful, more sincere, generous and orderly, more self-reliant and analytical. They felt less insecure and confused.

The control groups, on the other hand, showed little change in their perceptions of self. The most significant positive changes for these groups were in the categories with self descriptors such as caring and cheerful. There was also a decrease in the feelings of generosity and outgoingness, but these were not at the level we established as significant. Similarly, the Control groups showed a very slight decrease in feelings of insecurity. All other categories remained unchanged.

The picture that emerged of these two groups appears to demonstrate the positive effect of the EFS program on the participant's feeling of self in the areas of optimism, worth, and self-awareness. Table 2 shows the results of the statistical analysis of the data collected for the Personal Inventory Part B, Sentence Completion, Part C, Optimism-Pessimism, and the College Life Inventory instrument.

In Sample 2, statistical results showed that changes between pre- and post-test means for EFS students were significant for all three instruments, as measured by the t-test for independent means. The difference in means for the Control groups was significant only for the College Life Inventory in Sample 2 and the Optimism-Pessimism instrument in Sample 1. The increase in means of the EFS group in the Optimism-Pessimism scale was also significant in Sample 1 .

Sentence Completion responses increased positively at the end of participation in EFS. The most significant positive increase was in completing sentence 10 , "I think...." Since, after taking EFS, students completed this sentence with such a large increase in positive responses, it is most likely that their general feelings and attitudes had become positively influenced and reinforced as a result of this experience.

The increase in positive responses seen for the College Life Inventory supports the original hypothesis that participation in EFS increases positive 
Table 2

Pre- and Post- test Means for Three Instruments

pre post $\underline{\mathrm{t}(\mathrm{df})}$ pre post $\underline{\mathrm{t}(\mathrm{df})}$

Sample 1.

$(\mathrm{df})_{4}=$

142

34

Optimism-

Pessimism

$\mathrm{sd}_{5}=$

$6.74 \quad 7.06$

$2.09_{2} \quad 6.58 \quad 6.00$

1.82

1.48

\section{Sample 2.}

$(\mathrm{df})=$

34

Sentence-

Completion

6.16

6.72

$2.73_{1}$

$\mathrm{NS}_{3}$

sd $=$

2.31

Optimism-

Pessimism

sd $=$

$6.81 \quad 7.22 \quad 2.50_{1}$

NS

1.85

College Life

Inventory

4.37

4.79

$2.15_{2} \quad 5.08$

4.80

$2.43_{1}$

sd $=$

2.20

0.67

$1 \quad \mathrm{p}<.01$

$2 \quad \mathrm{p}<.03$

3 NS means not significant

4 df means degrees of freedom

5 sd is the standard deviation of the population 
attitudes toward life in general. This is further supported, in both EFS samples, by the significantly positive increase in ratings on the O-P Scale. Two sample support of this measure clearly and strongly upholds the original hypothesis that there would be a more positive outlook towards life for EFS students at the end of the semester. The Control group's significantly lower mean score on the post-test of Sample 1 may be due to a general feeling of pessimism about their future, in contrast to the more buoyant attitude expressed by the EFS students because of the support provided by the program. No change occurred for the Control group of Sample 2 on this measure.

In Sample 1 there was a significant difference in the post-means between the EFS (7.06) and Control groups (6.00) in the O-P instrument $(\mathrm{t}(176)=2.50$, $\mathrm{p}<.01$ ). Similarly, in Sample 2, although the change in the mean over the semester was not significant for the Control group, the difference between the post means of the EFS (6.72) and the Control group (5.43) was significant $(\mathrm{t}(171)=3.43, \mathrm{p}<.001)$.

The results of the EFS Expectation Scales are displayed in Table 3. The instruments were administered to EFS students only and the purpose was to see

Table 3

Pre- and Post- Mean Scores for the EFS Expectation Scales

\begin{tabular}{|c|c|c|c|c|c|c|}
\hline \multirow{3}{*}{$\mathrm{df}=$} & & \multicolumn{2}{|c|}{ Sample $1_{2}$} & \multicolumn{3}{|c|}{ Sample 2} \\
\hline & & \multicolumn{2}{|c|}{142} & \multicolumn{3}{|c|}{127} \\
\hline & pre & post & $\underline{t(d f)}$ & pre & post & \\
\hline Scale 1 & 64.6 & 62.6 & $2.6 \mathrm{I}_{3}$ & 64.9 & 64.4 & $\mathrm{NS}_{1}$ \\
\hline Scale 2 & $72.5^{\circ}$ & 70.3 & $2.35_{3}$ & 72.7 & 71.9 & NS \\
\hline
\end{tabular}

1 NS means the change is not significant

2 The significant difference in the means in Sample 1 is due to confusion in issuing instructions during the administration of the pre-test. The problem was resolved by the post-test, but it leaves the results for Sample 1 nebulous.

$3 \quad \mathrm{p}<.01$ 
if the students' expectations about the course were met. As described previously, a mean score greater than 60 indicates positive expectations. The hypothesis was that there would be no difference between pre- and post- mean scores, indicating that the expectations for the course had been met.

The results for Sample 1 should be viewed with caution because there was some confusion in the instructions during the administration of the pre-test. These problems were resolved and the results for Sample 2 showed no significant difference in the means. This result upholds the hypothesis that the EFS course lived up to the students' expectations.

\section{Conclusion}

There is strong evidence suggesting that the EFS program made a significant difference in the self-concept of the freshmen who participated in the program. The profiles of these students showed increased self-awareness and a more optimistic view of life in general after completing the EFS program.

The problems of incoming freshmen, which were touched upon somewhat at the beginning of this article, will not diminish. Even in small, user-friendly, college environments, the life-affecting choices that these youngsters must make are awesome. Plunged into a new, highly competitive arena, freshmen must make these life-affecting choices fairly quickly. The consequences of these choices are not trivial; they can either enhance, or seriously impede students' lives.

The more self-awareness a person has, the more likely he or she is to make choices that are "right". The EFS program seems to be effective in increasing self awareness in freshmen.

The program could be used productively in several ways. It could be run as a pre-academic semester program, in summer school, for example. The program is very flexible so the length of time required could be concentrated into as little as one week or, as this article describes, as long as a semester. It could be given as an elective during the first academic semester. The physical requirements for the program are virtually nil. It adapts well to any environment, small colleges and large universities alike.

\section{References}

Anastasi, A. (1968). Psychological testing. London: Macmillan Co.

Brown, R.D. (1983). Getting started. Journal of College Student Personnel, 24, 387-388.

Burke, J.P, et al. (1985). The role of self-esteem in affective reactions to achievement-related situations. Educational and Psychological Research, 5 , 191-203. 
Combs, C. (1964). Perception of self and scholastic underachievement in the academically capable. The Personnel and Guidance Journal. XLII, 42-51.

Coopersmith, S. (1968). Studies in self-esteem. Scientific American, 218, 96-102.

Devlin, J. (1961). A dictionary of synonyms and antonyms. New York: Popular Library.

Fink, M.B. (1962). Self concept as it related to academic underachievement. California Journal of Educational Research, XII, 57-62.

Hummel, J.W. and Cecil, N.L. (1984). Self-concept and academic progress. Journal of Humanistic Education and Development, 23, 12-22.

Pottebaum, S.M., et al. (1986). Is there a causal relation between self-concept and academic achievement?. Journal of Educational Research, 79, 140-44.

Swell, L. (1990). Educating for success: Theory manual. Dubuque, Iowa: Kendall Hunt Publishing Co.

Swell, L. (1990). Educating for success: Workbook. Dubuque, Iowa: Kendall Hunt Publishing Co.

Swell, L. (1990). Educating for success: Leaders guide. Dubuque, Iowa: Kendall Hunt Publishing Co.

Tunney, J. (1984). Self-esteem and participation: 2 basics for student achievement. NASSP Bulletin, 68, 117-21. 